\title{
Fabrication of Orderly Copper Particle Arrays on a Multi-Electrolyte-Step Anodic Aluminum Oxide Template
}

\author{
Chun-Ko Chen, ${ }^{1}$ Der-Sheng Chan, ${ }^{2}$ Cheng-Chung Lee, ${ }^{1}$ and Sheng-Hui Chen ${ }^{1}$ \\ ${ }^{1}$ Department of Optics and Photonics, National Central University, 300 Chung-Da Road, Chung-Li 32001, Taiwan \\ ${ }^{2}$ Department of Chemical and Materials Engineering, Lee-Ming Institute of Technology, Lizhuan Road, New Taipei City 24305, Taiwan \\ Correspondence should be addressed to Sheng-Hui Chen; ericchen@dop.ncu.edu.tw
}

Received 4 September 2013; Revised 4 November 2013; Accepted 6 November 2013

Academic Editor: Guangyu Zhao

Copyright (c) 2013 Chun-Ko Chen et al. This is an open access article distributed under the Creative Commons Attribution License, which permits unrestricted use, distribution, and reproduction in any medium, provided the original work is properly cited.

\begin{abstract}
A multi-electrolyte-step (MES) anodic aluminum oxide (AAO) method was used to achieve nanochannel arrays with good circularity and periodic structure. The nano-channel array fabrication process included immersion in a phosphoric acid solution with a 120-150 bias voltage. Bowl-shaped structures were then formed by removing the walls of the nano-channel arrays. The nanochannel arrays were grown from the bottom of the bowl structure in an oxalic solution using a $50 \mathrm{~V}$ bias voltage. A comparison of this new MES process with the one-step and five-step AAO process showed a $50 \%$ improvement in the circularity over the onestep process. The standard deviation of the average period in the MES array was $25 \mathrm{~nm}$ which is less than that of one-step process. This MES method also took $1 / 4$ of the growing time of the five-step process. The orderliness of the nano-channel arrays for the five-step and MES process was similar. Finally, $\mathrm{Cu}$ nanoparticle arrays with a $200 \mathrm{~nm}$ period were grown using an electroplating process inside the MES nano-channel arrays on fluorine doped tin oxide glass. Stronger surface plasmon resonance absorption from $550 \mathrm{~nm}$ to $750 \mathrm{~nm}$ was achieved with the MES process than was possible with the one-step process.
\end{abstract}

\section{Introduction}

In recent years, surface plasmon resonance (SPR) in nanoparticle array has attracted a lot of attention because of the adjustable absorption band $[1,2]$. SPR assisted energy conversion in dye-sensitized solar cell has also been studied [3]. The SPR effect is dependent on the shape and the arrangement of the nanoparticles but it is not easy to achieve good circularity and periodicity in metallic nanoparticle arrays. It has been shown that carbon nanotubes, nanoparticles, quantum dots, and nanopillars can be grown in nanochannel arrays utilizing various methods for their fabrication [4]. The use of the anodic aluminum oxide (AAO) method for the fabrication of nanochannel arrays to nanoparticle arrays has matured [5]. However, the positioning of the nanochannel arrays grown using the AAO method is random making it very difficult to control the hole quality and to form orderly arrays. There have been some methods for growing good quality AAO nanochannel arrays developed. They require either an increase in circularity or improvement in the period of the channels, so it becomes a long process [6]. For example, in the multistep AAO process [7], channels are repeatedly grown and removed to achieve periodic arrays. The problem is the thickness of the raw material, $\mathrm{Al}$, has to be greater than $1 \mu \mathrm{m}$, which is too thick for the deposition of a good quality of film. Another method involves using mixed electrolytes to improve the circularity of the nanochannel arrays. The limitations of this method are that the period of the arrays that can be grown is less than $150 \mathrm{~nm}$ and the arrangement of the arrays is irregular $[8,9]$. A nanoimprinting method can be applied to control and regularize the positions of the nanochannel arrays [10], but the imprinting mold is easily broken during the imprinting process. The use of an atomic force microscope (AFM) for prepatterning [11] is good, but the working area is very small. In this study a multi-electrolyte-step (MES) method was applied to improve the circularity and period of the arrays. The goal was to grow orderly nanochannel arrays in a simpler and more useful fashion. A nanochannel template was applied for the masking of antireflectance structures on a large area [12] 
for the production of omnidirectional reflectors [13]. Finally, periodic copper particles with larger periods were grown in the MES nanochannel arrays on fluorine doped tin oxide (FTO) glass and the absorption of the spectrum was in the visible region due to SPR.

\section{Definition and Simulation}

Nanochannel arrays for periodic structure applications have to be precisely ordered with a regular period and good circularity $[14,15]$. The circularity $f_{\text {circ }}$ of the nanochannel arrays can be defined as follows:

$$
f_{\text {circ }}=\frac{4 \pi A}{P^{2}}
$$

where $P$ is the perimeter of a hole and $A$ is its area. When the circularity is 1 , the hole is a perfect circle. When the hole flattens, the circularity approaches 0 . In the past, AAO nanochannel arrays were grown in phosphoric or oxalic acid. The results of analysis of the circularities of the holes produced from one-step AAO processes [16-27] are shown in Figure 1. It can be seen that it is difficult to grow good quality arrays with a period in the range from 150 to $300 \mathrm{~nm}$ in phosphoric acid using the traditional AAO method. It has also been proven that better quality arrays can be produced using an AAO process with oxalic acid, with most holes being in the upper 0.8 range in circularity. We devise an MES method designed to grow orderly nanochannel arrays in a simpler and more useful fashion, which produces arrays with improved circularity and periodicity. We first simulated a $200 \mathrm{~nm}$ bowl structure and applied an added bias of $50 \mathrm{~V}$ to see if the AAO process could be applied theoretically. The simulation results obtained by finite element analysis are shown in Figure 2. Parkhutik and Shershulsky [28] and Houser and Hebert [29] proposed a model that can suitably describe the charge characteristics of an AAO electrode. This model [30] was also used to analyze the potential distribution inside the anode. The results in Figure 2 show the distribution of the potential and gradient of the potential, where $A$ indicates the position at the top of curve S, B at the middle, and $\mathrm{C}$ at the bottom. The value of the gradient of the potential at $\mathrm{A}$ is higher than that at $\mathrm{B}$ or $\mathrm{C}$. The results indicate that the maximum oxidation reaction rate occurs at $A$, due to the geometrical symmetry effect. According to the simulation results, the highest bias occurred at the central position of the bowl structure, with a new channel growing there due to the electrochemical reaction. Thus, we could design a process for the growth of large-period nanochannel arrays at lower voltages.

\section{Experiments}

In the experimental process, $99.5 \%$ aluminum foils were used as the substrates which were electropolished in an $\mathrm{H}_{3} \mathrm{PO}_{4} / \mathrm{H}_{2} \mathrm{SO}_{4} /$ di water $(2: 2: 1)$ solution; the roughness of the substrate surface could range from 30 to $13.1 \mathrm{~nm}$. After substrate cleaning, the MES process was used to grow largeperiod nanochannel arrays in a $10 \mathrm{wt} \%$ phosphoric acid at

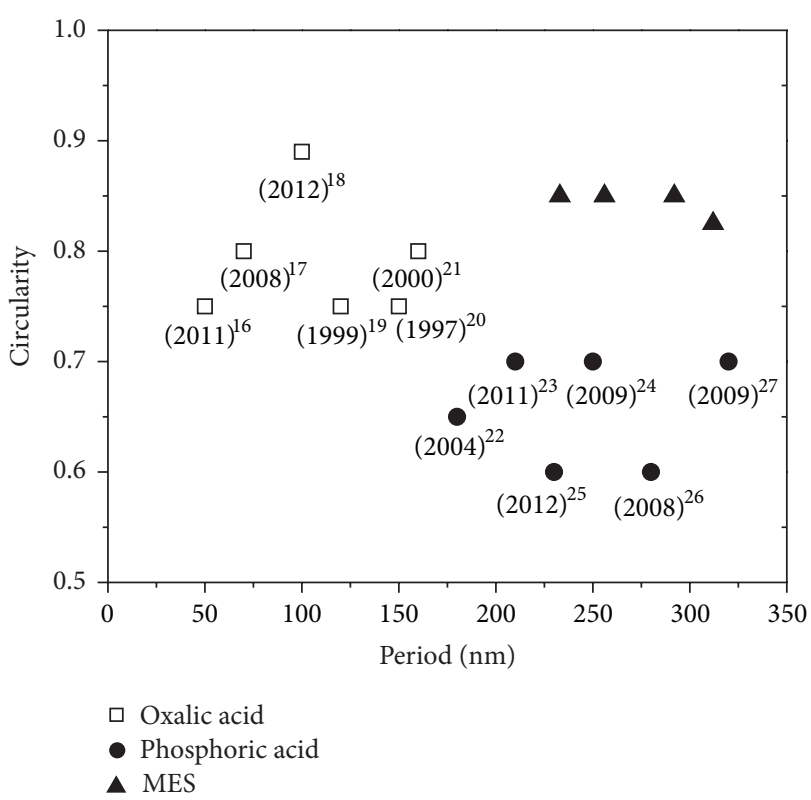

FIGURE 1: The analysis of circularity produced by AAO processes in oxalic acid and phosphoric acid.

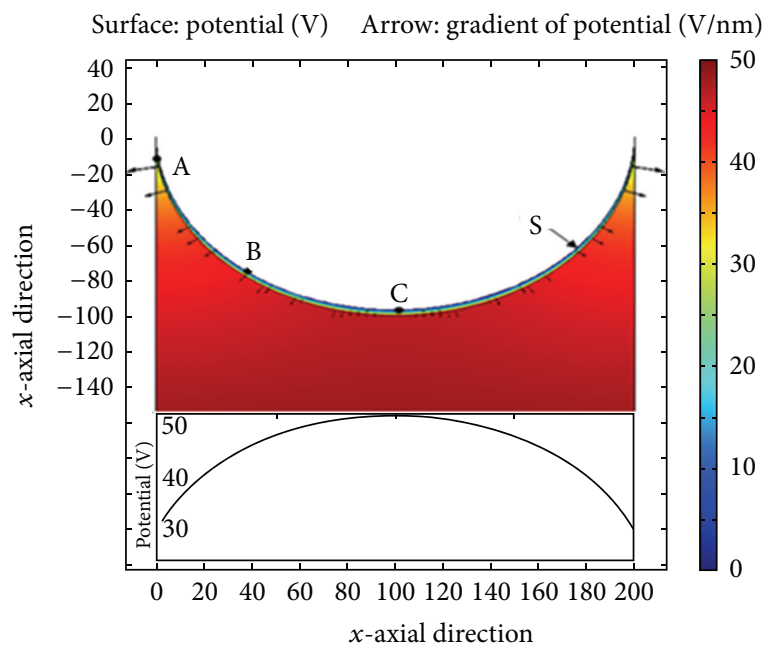

Figure 2: Distribution profiles of the potential with an applied voltage of $50 \mathrm{~V}$.

$4^{\circ} \mathrm{C}$ with the application of a bias voltage of $120-150 \mathrm{~V}$ for 10 minutes. The process design and its images are illustrated in Figure 3. The size of the holes was increased by chemical dissolution in a $0.5 \mathrm{M} \mathrm{NaOH}$ solution until the walls of the nanochannels were very thin, and bowl-shaped structures were formed by removing the walls of the nanochannel arrays. Nanochannel arrays were grown from the bottom of the bowl structure using a $50 \mathrm{~V}$ bias voltage in an oxalic acid solution for 30 minutes. It was easier to obtain nanochannels similar in shape to the circular holes in the oxalic acid solution than in the phosphoric acid solution. The results of the one-step AAO process were compared with the MES AAO 


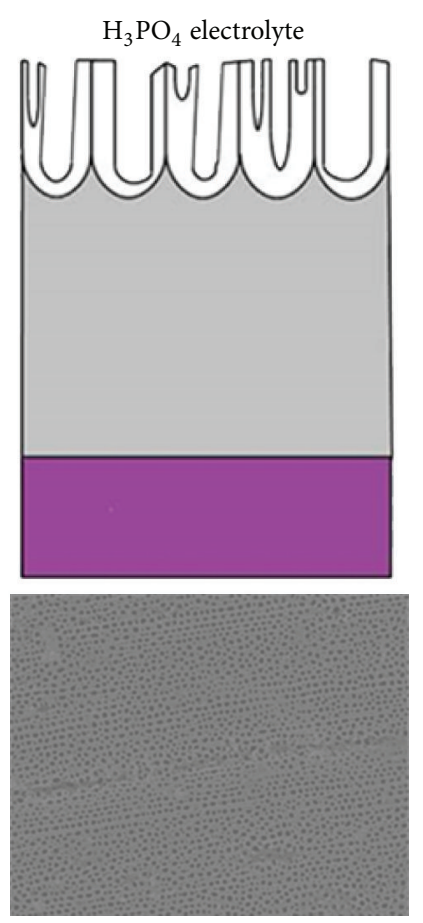

(a) Large period growing at $120-150$ volts
$\mathrm{NaOH}$ solution
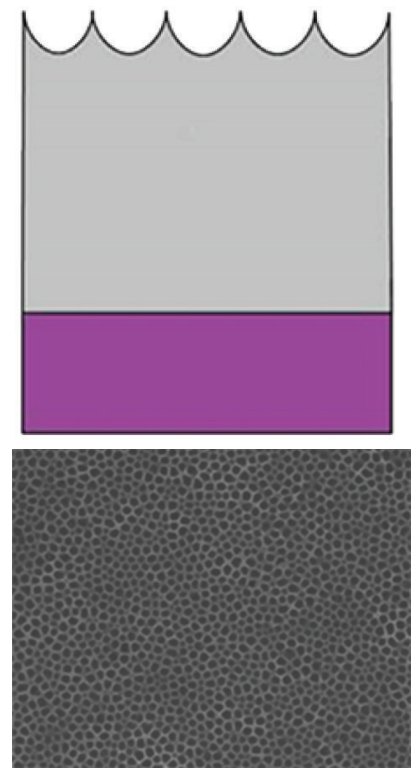

(b) Bowl-shaped structure
$\mathrm{H}_{2} \mathrm{C}_{2} \mathrm{O}_{4}$ electrolyte

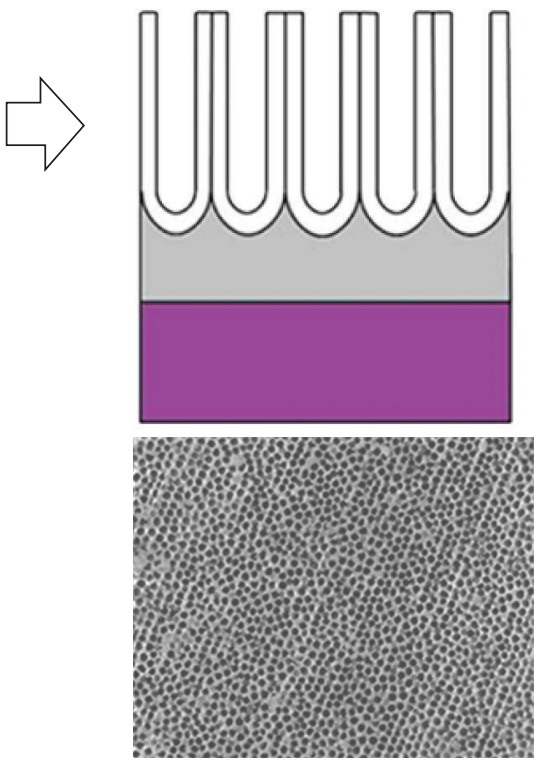

(c) The second growing at 50 volts

FIGURE 3: Nanochannel arrays with a large period growing at 120-150 volts and the second growing at 50 volts.

results. The one-step process involved growth in a $10 \mathrm{wt} \%$ phosphoric acid with a voltage of $120-150 \mathrm{~V}$ for 30 minutes. The holes increased in size to $0.5 \mathrm{M}$ when the $\mathrm{NaOH}$ solution was used. The one-step process was repeated five times (fivestep process); the results are also discussed in our study. It should be noted that these are the usual methods that have been used for the orderly growth of arrays in other studies. After this comparison, $300 \mathrm{~nm} \mathrm{Al} \mathrm{films} \mathrm{were} \mathrm{coated} \mathrm{onto}$ FTO glass after cleaning it with alcohol and acetone, and nanochannel arrays were grown using the one-step and MES process. $\mathrm{Cu}$ particles with a $200 \mathrm{~nm}$ period were grown at a bias voltage $1 \mathrm{~V}$ in the $0.05 \mathrm{MCuSO}_{4}$ solution utilizing an electroplating process, after which the AAO nanochannel arrays were removed by chemical dissolution. Finally, the spectra of the $\mathrm{Cu}$ nanoparticle arrays were measured by an integrating sphere spectrometer, where the scattered light could be collected by the integrating sphere. Then the absorption would be calculated. All of the chemicals used in the experiments were obtained from the Echo Chemical Co.

\section{Results and Discussion}

Analysis of the scanning electron microscope (SEM) images of nanochannel arrays grown through the traditional onestep and five-step processes and the MES AAO process was carried out. Figures 4(a)-4(d) show the nanochannel arrays produced after only 30 minutes of growth with the onestep process, with voltages of $120 \mathrm{~V}$ to $150 \mathrm{~V}$. The positions of the channels in the arrays thus grown are nonuniform, and the hole sizes are not orderly. It can be seen in Figures $4(\mathrm{e})-4(\mathrm{~h})$ that the nanochannel arrays grown by the five-step process are more orderly than those grown with the onestep process, but the process took about 3 hours. Figures 4(i)-4(l) show the nanochannel arrays grown with the MES process at voltages of $120-150 \mathrm{~V}$. The interpore distance of the nanochannel arrays increased following an increase in the bias voltage from 120 to $150 \mathrm{~V}$. The hole sizes of the nanochannels produced during the five-step and MES processes were larger than those produced in the one-step AAO process. The interpore distance also increased slower with the MES process than with the five-step process, being similar to that obtained from the one-step AAO process, as can be seen in Figure 4. We compared the circularity obtained with the MES, one-step, and five-step AAO methods, as determined by (1). The distribution curves for the circularity are shown in Figure 5. Analysis shows that the highest peak in Figure 5 is obtained for a circularity of $0.85-0.9$ obtained with 120-150 volts in MES. It was found that the circularity in the nanochannel arrays grown using the one-step AAO process $(120-140 \mathrm{~V}$ ) was less than $50 \%$ (ranging from 0.8 to 1.0) of that obtained with the five-step or MES methods. Using the MES AAO process, we were able to produce larger numbers of nanochannel arrays with good circularity at 120 $150 \mathrm{~V}$. Furthermore, the MES AAO process could grow more passable nanochannel arrays than with the one-step AAO process at $120-140 \mathrm{~V}$. As a result, we could achieve a high ratio of circularity and uniform nanochannel arrays with 


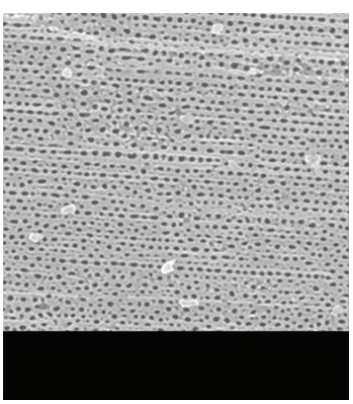

(a)

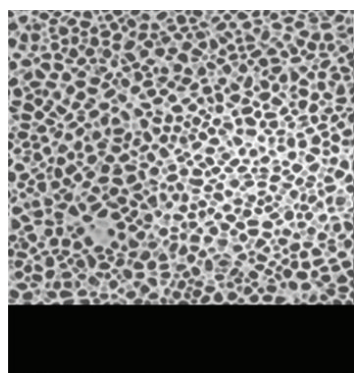

(e)

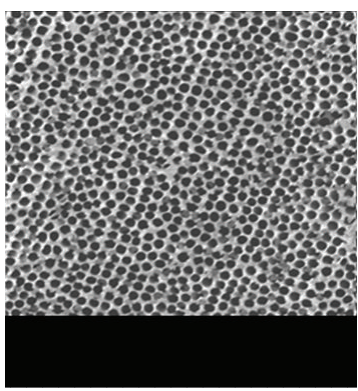

(i)

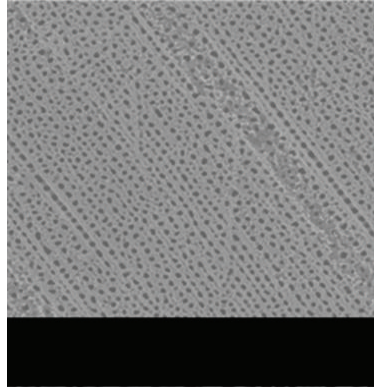

(b)

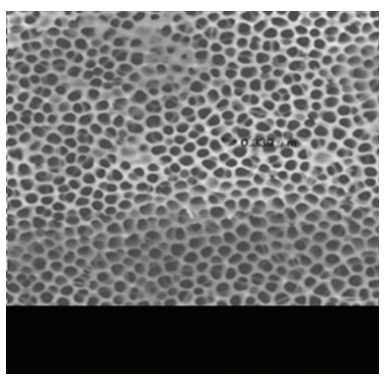

(f)

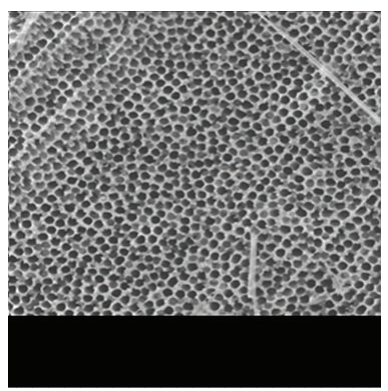

(j)

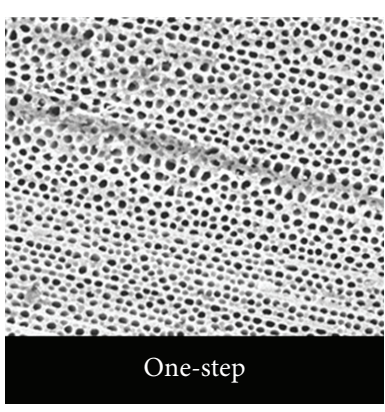

(c)

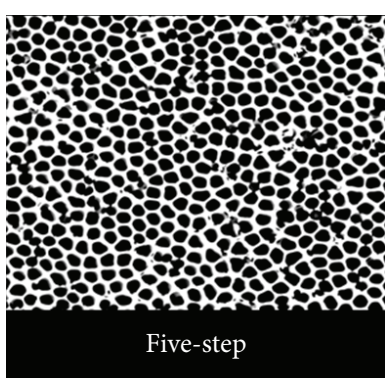

(g)

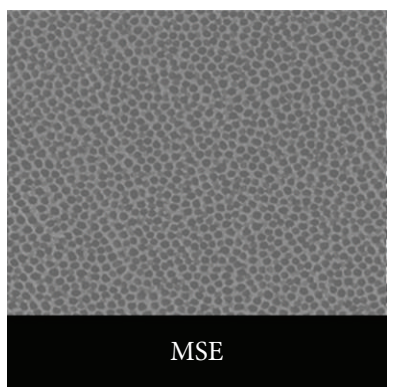

(k)

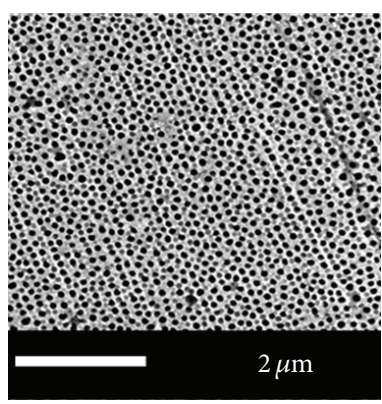

(d)

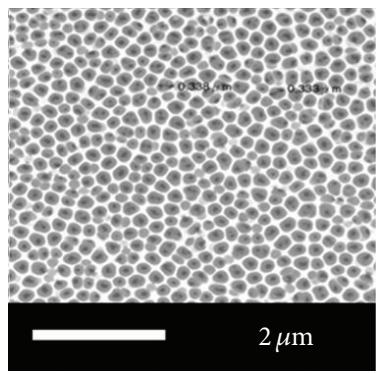

(h)

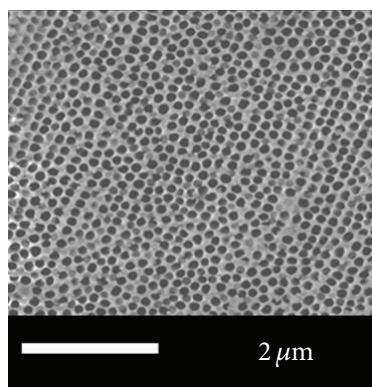

(1)

Figure 4: Nanochannel arrays grown with the one-step process at voltages of (a) 120, (b) 130, (c) 140, and (d) 150 V; five-step at voltages of (e) 120, (f) 130, (g) 140, and (h) $150 \mathrm{~V}$; and the MES process at voltages of (i) 120, (j) 130, (k) 140, and (l) $150 \mathrm{~V}$.

TABLE 1: The standard deviations and periods of nano-channel arrays produced at $120-150 \mathrm{~V}$ by the one-step, five-step, and MES processes.

\begin{tabular}{lccc}
\hline Bias & One-step & Five-step & MES \\
\hline $120 \mathrm{~V}$ & $202 \pm 92 \mathrm{~nm}$ & $213 \pm 22 \mathrm{~nm}$ & $233 \pm 18 \mathrm{~nm}$ \\
$130 \mathrm{~V}$ & $232 \pm 54 \mathrm{~nm}$ & $282 \pm 25 \mathrm{~nm}$ & $256 \pm 17 \mathrm{~nm}$ \\
$140 \mathrm{~V}$ & $261 \pm 84 \mathrm{~nm}$ & $332 \pm 15 \mathrm{~nm}$ & $292 \pm 15 \mathrm{~nm}$ \\
$150 \mathrm{~V}$ & $280 \pm 31 \mathrm{~nm}$ & $358 \pm 19 \mathrm{~nm}$ & $312 \pm 23 \mathrm{~nm}$ \\
\hline
\end{tabular}

the MES AAO process. In addition, the MES arrays had good circularity with a larger period compared to those obtained with the other methods, as can be seen (triangle dots) in Figure 1.

The Fast Fourier Transform (FFT) method was used to analyze the average period and the standard deviation of period which is the distance between the interpore centers. The positional shift for the one-step process was larger than
$50 \mathrm{~nm}$ at $120-140 \mathrm{~V}$, but less than $25 \mathrm{~nm}$ at $120-150 \mathrm{~V}$ for the five-step and MES processes, as shown in Figure 6. The results prove that the MES method was able to produce better periodic nanochannel arrays than the one-step method with a shorter growing time, allowing for a large-period design; see Figure 6. The average period for the one-step, five-step, and MES processes was also analyzed. In the five-step AAO process, the period increased slowly from 202 to $280 \mathrm{~nm}$, then more quickly from 213 to $358 \mathrm{~nm}$, while in the MES process the period increased from 233 to $312 \mathrm{~nm}$, as shown in Table 1. This method had the advantage of increasing the period by repeating the growth steps. Figures $7(\mathrm{a})$ and $7(\mathrm{~b})$ show $\mathrm{Cu}$ nanoparticle arrays with a $200 \mathrm{~nm}$ period grown on FTO glass by the electroplating process with the one-step and MES nanochannel processes. The diameters of the copper particles were between 100 and $150 \mathrm{~nm}$ with $120-150$ volts in one-step and between 150 and $225 \mathrm{~nm}$ in MES process. We can find that the $\mathrm{Cu}$ nanoparticle array has better period and circularity in Figure 7(b) than in Figure 7(a). Figure 8 


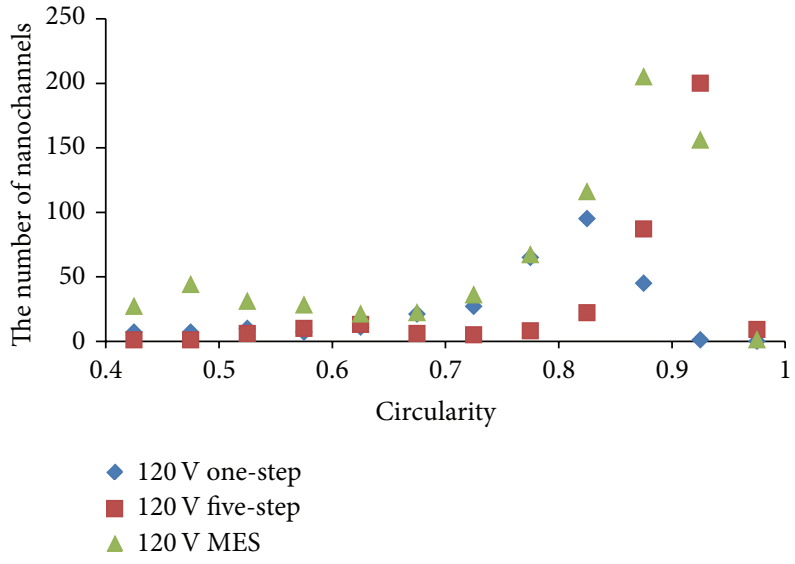

(a)

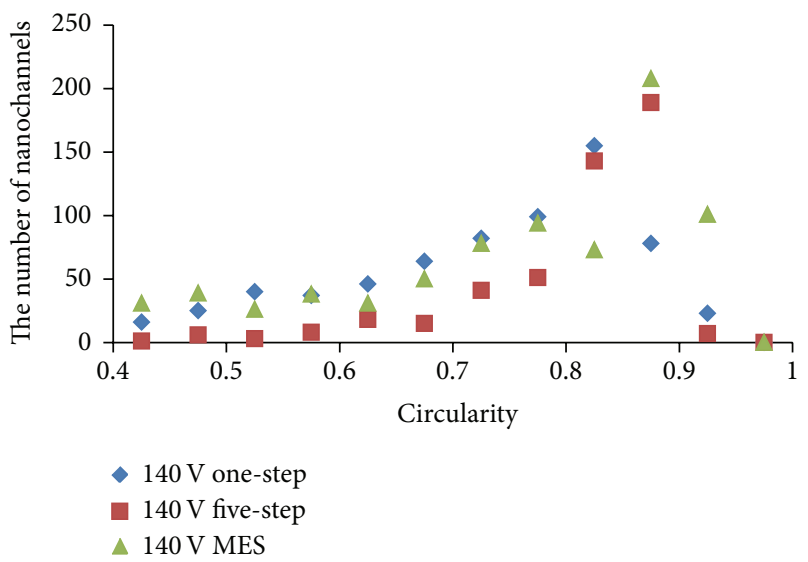

(c)
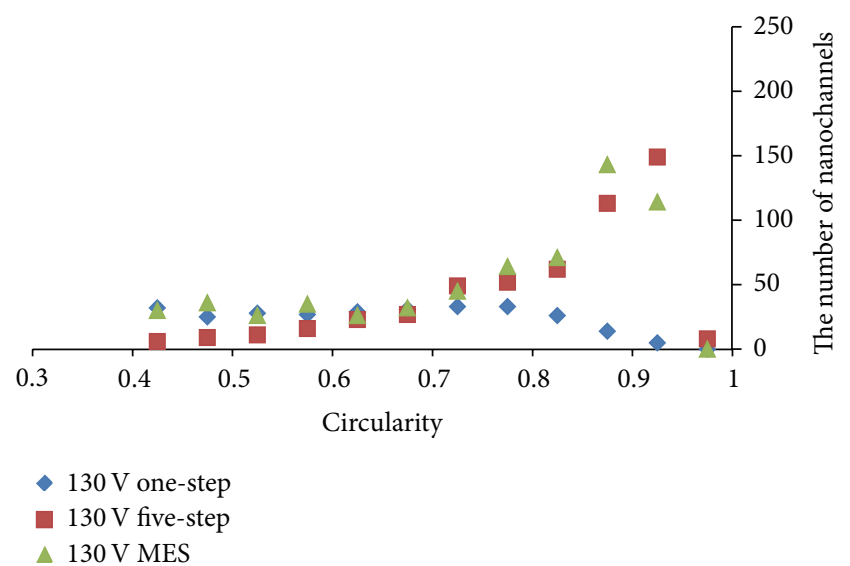

$\triangle 130 \mathrm{~V}$ MES

(b)

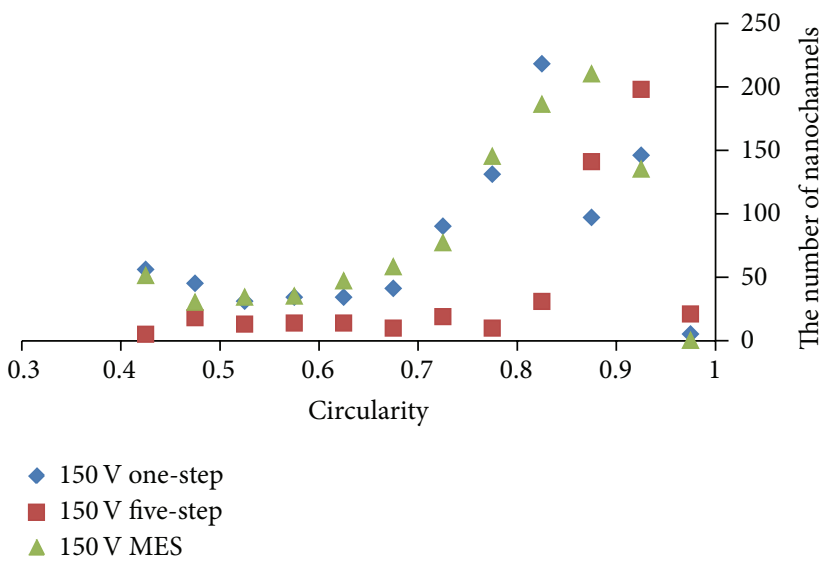

(d)

FIGURE 5: Circularity analysis for the one-step, five-step, and MES processes with 120-150 V.

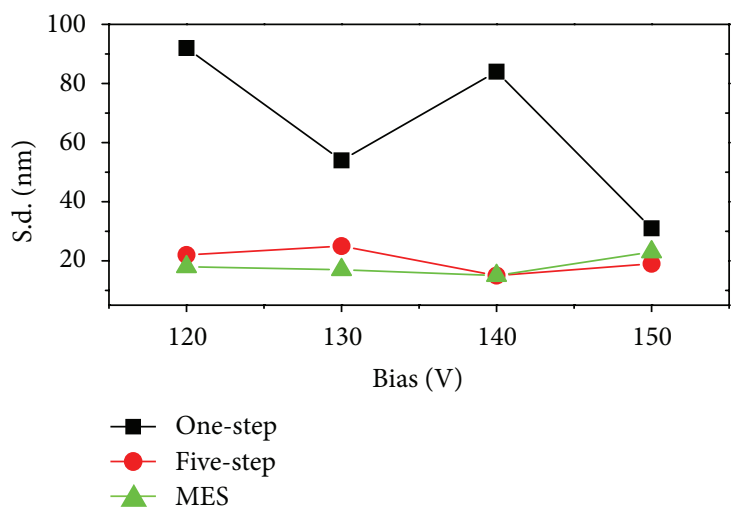

(a)

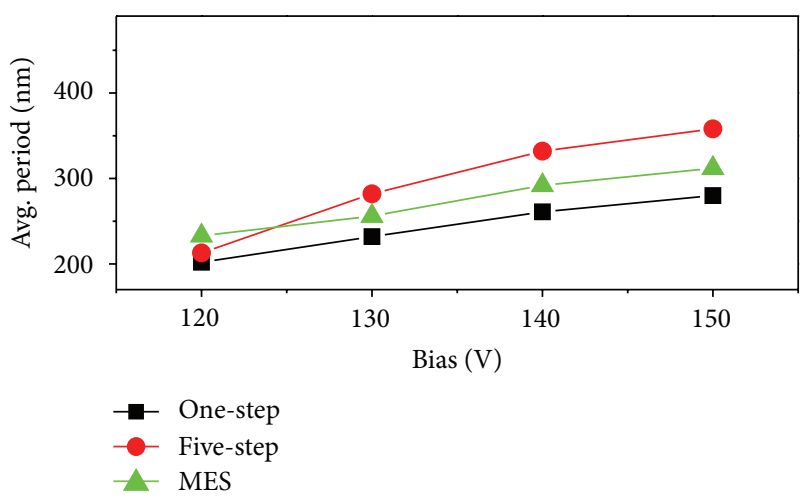

(b)

FIgURE 6: Average periods of AAO nanochannel arrays with a standard deviation (s.d.) at 120-150 V for the one-step, five-step, and MES $\mathrm{AAO}$ processes.

shows the absorption spectra of the $\mathrm{Cu}$ nanoparticle arrays grown with the one-step and the MES AAO processes. The results show that the SPR absorption from $550 \mathrm{~nm}$ to $750 \mathrm{~nm}$ is stronger for the arrays produced with the MES process than with the one-step process.

\section{Conclusion}

This study proves that more orderly periodic nanochannel arrays can be produced with an MES process combining two electrolytes of phosphoric acid and oxalic acid. The analysis 


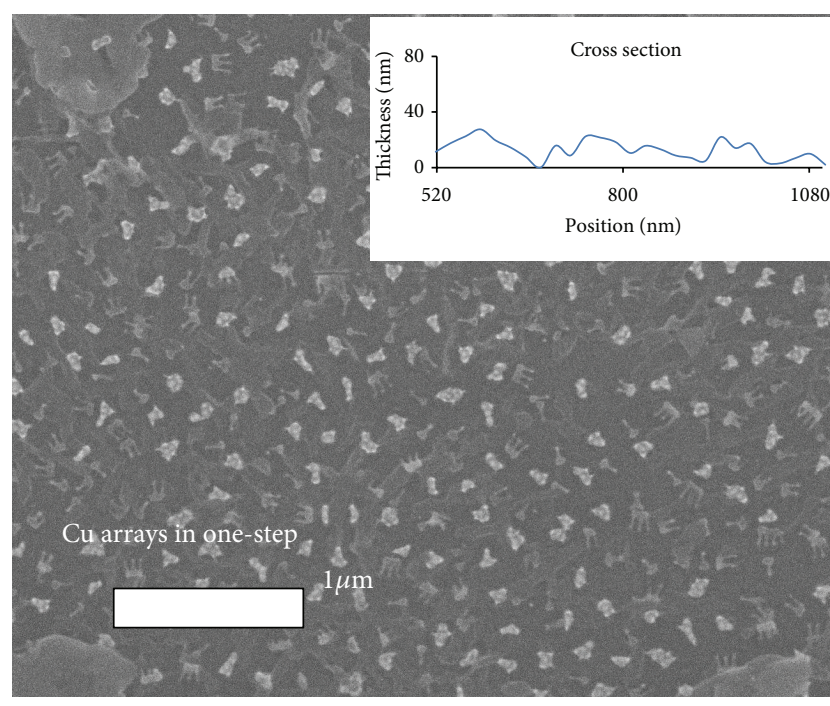

(a)

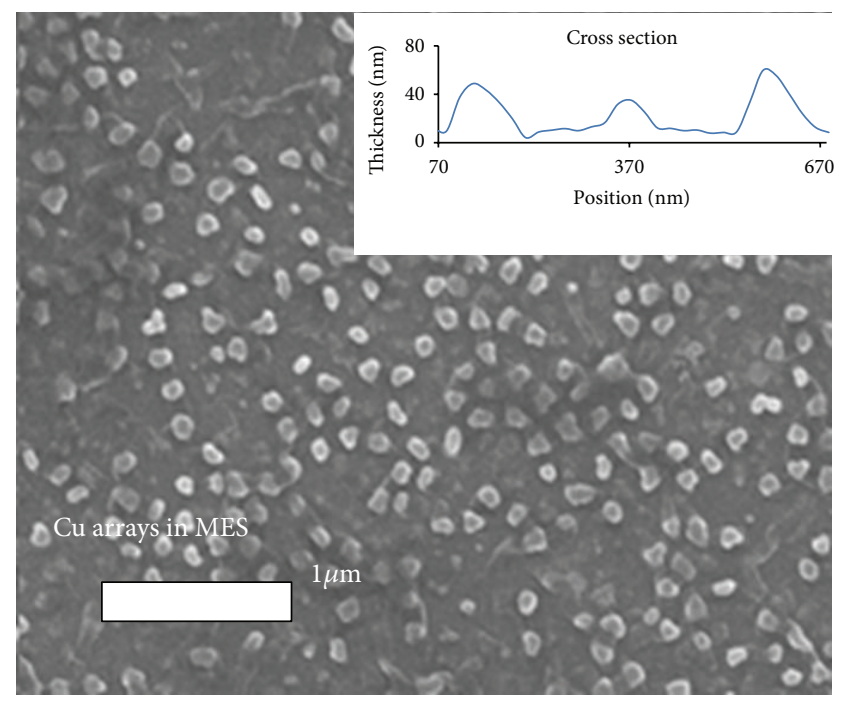

(b)

FIGURE 7: Cu nanoparticle arrays with a $200 \mathrm{~nm}$ period produced with (a) the one-step and (b) with MES AAO processes.

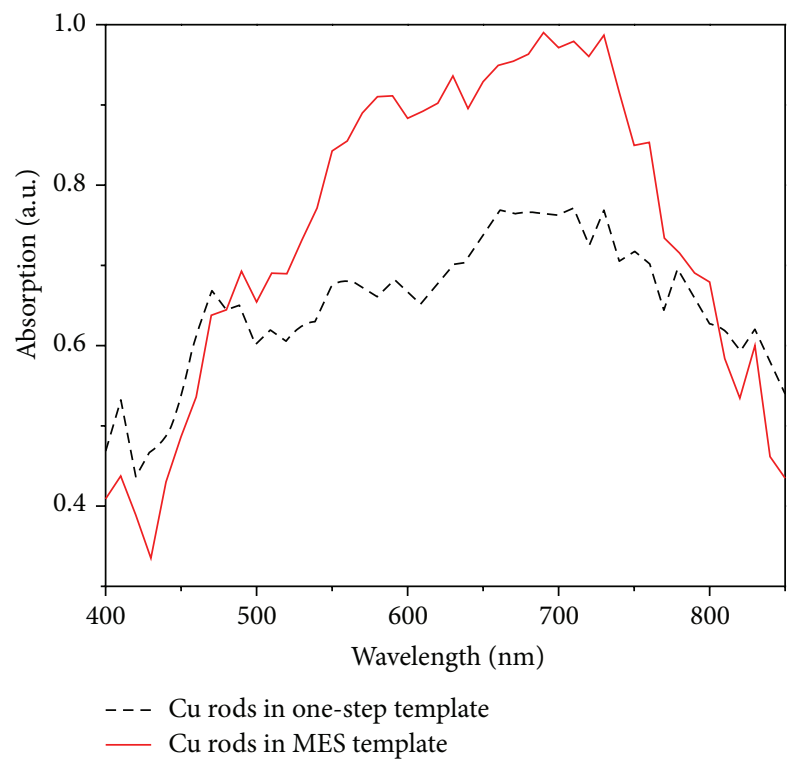

FIgURE 8: Absorption spectra for the $\mathrm{Cu}$ nanoparticle arrays produced by the MES and one-step AAO processes.

shows better circularity of $0.85-0.9$ with $120-150 \mathrm{~V}$ in the MES process, with a standard deviation of the average period of less than $25 \mathrm{~nm}$. The advance in the development of orderly nanochannel arrays with the MES method is similar to that achieved with the longer five-step process. Finally, $\mathrm{Cu}$ nanoparticle arrays with a period of $200 \mathrm{~nm}$ were grown in AAO templates on FTO glass using the MES process. The SPR absorption ranged from $550 \mathrm{~nm}$ to $750 \mathrm{~nm}$, stronger than with the one-step process.

\section{Acknowledgment}

The authors would like to thank the National Science Council of Taiwan for their financial support of this research under
Contract nos. NSC 101-2221-E-008-052 and 101-3113-P-008009.

\section{References}

[1] S. Linic, P. Christopher, and D. B. Ingram, "Plasmonic-metal nanostructures for efficient conversion of solar to chemical energy," Nature Materials, vol. 10, no. 12, pp. 911-921, 2011.

[2] J. F. Sanchez-Ramírez, "Preparation and optical absorption of colloidal dispersion of Au/Cu nanoparticles," Superficies $Y$ Vacio, vol. 15, pp. 16-18, 2002.

[3] B. Ding, B. J. Lee, M. Yang, H. S. Jung, and J. K. Lee, "SurfacePlasmon Assisted Energy Conversion in Dye-Sensitized Solar Cells," Advanced Energy Materials, vol. 1, no. 3, pp. 415-421, 2011.

[4] R.-L. Zong, J. Zhou, B. Li, M. Fu, S.-K. Shi, and L.-T. Li, "Optical properties of transparent copper nanorod and nanowire arrays embedded in anodic alumina oxide," Journal of Chemical Physics, vol. 123, no. 9, Article ID 094710, 2005.

[5] Y. Zhang, W. Xu, S. Xu, G. Fei, Y. Xiao, and J. Hu, "Optical properties of $\mathrm{Ni}$ and $\mathrm{Cu}$ nanowire arrays and $\mathrm{Ni} / \mathrm{Cu}$ superlattice nanowire arrays," Nanoscale Research Letters, vol. 7, no. 1, p. 569, 2012.

[6] C.-K. Chung, T. Y. Liu, and W. T. Chang, "Effect of oxalic acid concentration on the formation of anodic aluminum oxide using pulse anodization at room temperature," Microsystem Technologies, vol. 16, no. 8-9, pp. 1451-1456, 2010.

[7] C. Y. Han, G. A. Willing, Z. Xiao, and H. H. Wang, "Control of the anodic aluminum oxide barrier layer opening process by wet chemical etching," Langmuir, vol. 23, no. 3, pp. 1564-1568, 2007.

[8] Y. Jia, H. Zhou, P. Luo, S. Luo, J. Chen, and Y. Kuang, "Preparation and characteristics of well-aligned macroporous films on aluminum by high voltage anodization in mixed acid," Surface and Coatings Technology, vol. 201, no. 3-4, pp. 513-518, 2006.

[9] S. Shingubara, K. Morimoto, H. Sakaue, and T. Takahagi, "Self-organization of a porous alumina nanohole array using a sulfuric/oxalic acid mixture as electrolyte," Electrochemical and Solid-State Letters, vol. 7, no. 3, pp. E15-E17, 2004. 
[10] C. Y. Liu, A. Datta, and Y. L. Wang, "Ordered anodic alumina nanochannels on focused-ion-beam-prepatterned aluminum surfaces," Applied Physics Letters, vol. 78, no. 1, pp. 120-122, 2001.

[11] S. Shingubara, Y. Murakami, K. Morimoto, and T. Takahagi, "Formation of aluminum nanodot array by combination of nanoindentation and anodic oxidation of aluminum," Surface Science, vol. 532-535, pp. 317-323, 2003.

[12] S. H. Chan, C. K. Chen, S. Z. Tseng, C. H. Hsu, and W. H. Cho, "Atomic layer deposition of aluminum-doped zinc oxide films for the light harvesting enhancement of a nanostructured silicon solar cell," The Journal of Vacuum Science and Technology A, vol. 31, no. 1, pp. 01A125-01A128, 2013.

[13] C. K. Chen, Y. C. Huang, C. C. Lee, and S. H. Chen, "Omnidirectional reflectors for UV LED using symmetric autocloning method," Optical Review, vol. 20, no. 2, pp. 141-144, 2013.

[14] I. Cavarretta, C. O'Sullivan, and M. R. Coop, "Applying 2D shape analysis techniques to granular materials with 3D particle geometries," in Proceedings of the 6th International Conference on Micromechanics of Granular Media, Powders and Grains 2009, pp. 833-836, July 2009.

[15] A. P. Z. Stevenson, D. B. Bea, S. Civit, S. A. Contera, A. I. Cerveto, and S. Trigueros, "Three strategies to stabilise nearly monodispersed silver nanoparticles in aqueous solution," Nanoscale Research Letters, vol. 7, pp. 151-158, 2012.

[16] O. Sanz, F. J. Echave, J. A. Odriozola, and M. Montes, "Aluminum anodization in oxalic acid: controlling the texture of $\mathrm{Al}_{2} \mathrm{O}_{3} / \mathrm{Al}$ monoliths for catalytic aplications," Industrial and Engineering Chemistry Research, vol. 50, no. 4, pp. 2117-2125, 2011.

[17] A. Belwalkar, E. Grasing, W. Van Geertruyden, Z. Huang, and W. Z. Misiolek, "Effect of processing parameters on pore structure and thickness of anodic aluminum oxide (AAO) tubular membranes," Journal of Membrane Science, vol. 319, no. 1-2, pp. 192-198, 2008

[18] K. Ersching, E. Dorico, R. C. da Silva et al., "Surface and interface characterization of nanoporous alumina templates produced in oxalic acid and submitted to etching procedures," Materials Chemistry and Physics, vol. 137, pp. 140-146, 2012.

[19] A. P. Li, F. Muller, A. Birner, K. Nielsch, and U. Gosele, "Fabrication and microstructuring of hexagonally ordered twodimensional nanopore arrays in anodic alumina," Advanced Materials, vol. 11, no. 6, pp. 483-487, 1999.

[20] H. Masuda, H. Yamada, M. Satoh, H. Asoh, M. Nakao, and T. Tamamura, "Highly ordered nanochannel-array architecture in anodic alumina," Applied Physics Letters, vol. 71, no. 19, pp. 1012, 1997.

[21] A. P. Li, F. Müller, and U. Gösele, "Polycrystalline and monocrystalline pore arrays with large interpore distance in anodic alumina," Electrochemical and Solid-State Letters, vol. 3, no. 3, pp. 131-134, 2000.

[22] B. Yu, Y. Gao, and H. Li, "Fabrication and optical characterization of poly(2,5-di-n-butoxyphenylene) nanofibril arrays," Journal of Applied Polymer Science, vol. 91, no. 1, pp. 425-430, 2004.

[23] K.-L. Lai, M.-H. Hon, and I.-C. Leu, "Fabrication of ordered nanoporous anodic alumina prepatterned by mold-assisted chemical etching," Nanoscale Research Letters, vol. 6, pp. 157$162,2011$.

[24] A. Nourmohammadi, S. J. Asadabadi, M. H. Yousefi, and M. Ghasemzadeh, "Photoluminescence mission of nanoporous anodic aluminum oxide films prepared in phosphoric acid," Nanoscale Research Letters, vol. 7, pp. 689-695, 2012.
[25] C.-G. Kuo and C.-C. Chen, "Technique for self-assembly of tin nano-particles on anodic aluminum oxide (AAO) templates," Materials Transactions, vol. 50, no. 5, pp. 1102-1104, 2009.

[26] W. Chen, J.-S. Wu, and X.-H. Xia, "Porous anodic alumina with continuously manipulated pore/cell size," ACS Nano, vol. 2, no. 5, pp. 959-965, 2008.

[27] L. Zaraska, G. D. Sulka, and M. Jaskua, "Properties of nanostructures obtained by anodization of aluminum in phosphoric acid at moderate potentials," Journal of Physics: Conference Series, vol. 146, Article ID 012020, pp. 012020-012026, 2009.

[28] V. P. Parkhutik and V. I. Shershulsky, "Theoretical modelling of porous oxide growth on aluminum," Journal of Physics D, vol. 25, pp. 1258-1263, 1992.

[29] J. E. Houser and K. R. Hebert, "Modeling the potential distribution in porous anodic alumina films during steady-state growth," Journal of the Electrochemical Society, vol. 153, no. 12, Article ID 078612JES, pp. B566-B573, 2006.

[30] H. Chen, D. S. Chan, C. K. Chen, T. H. Chang, Y. H. Lai, and C. C. Lee, "Nanoimprinting pre-patterned effects on anodic aluminum oxide," Japanese Journal of Applied Physics, vol. 49, no. 1, pp. 015201-015204, 2010. 

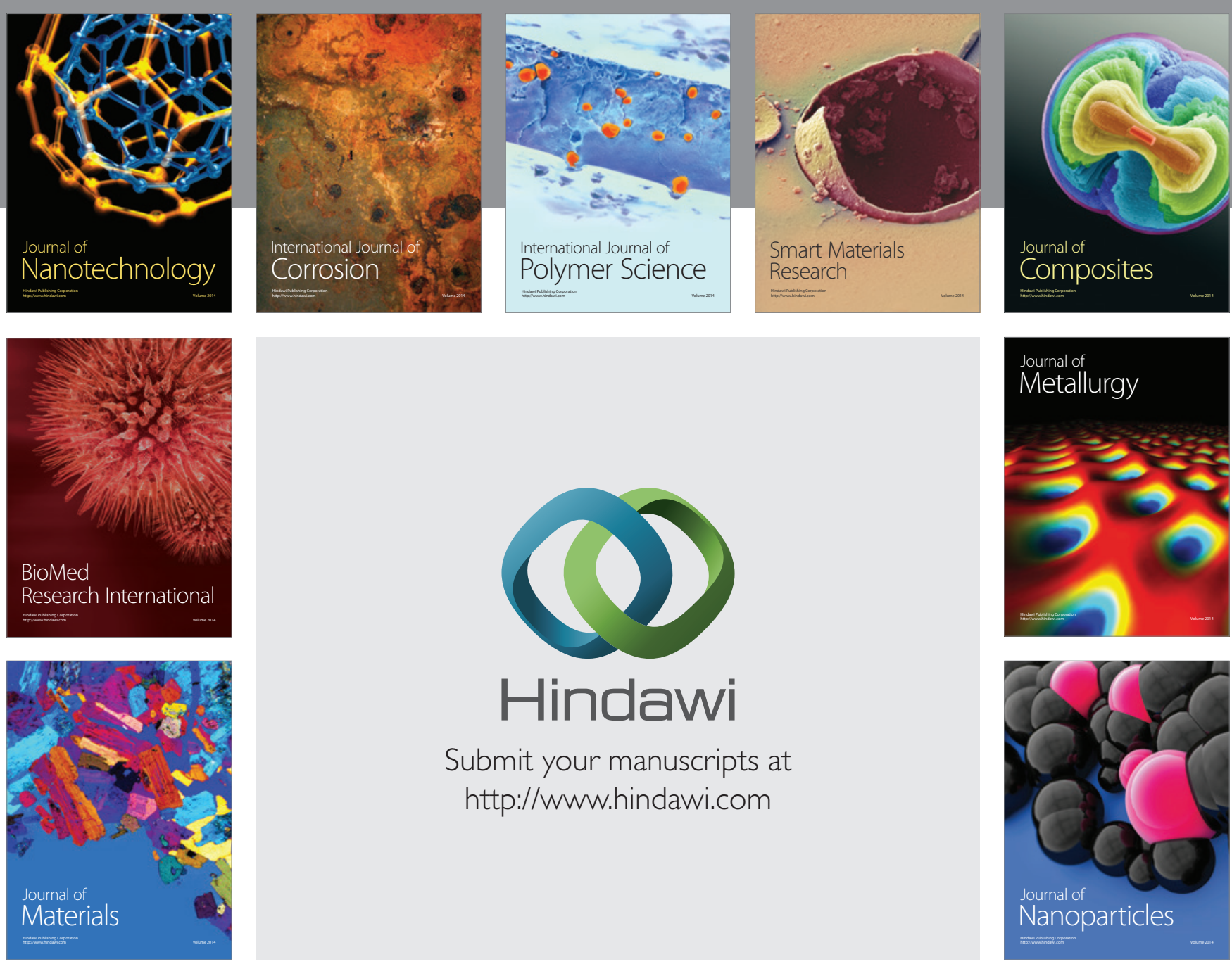

Submit your manuscripts at http://www.hindawi.com
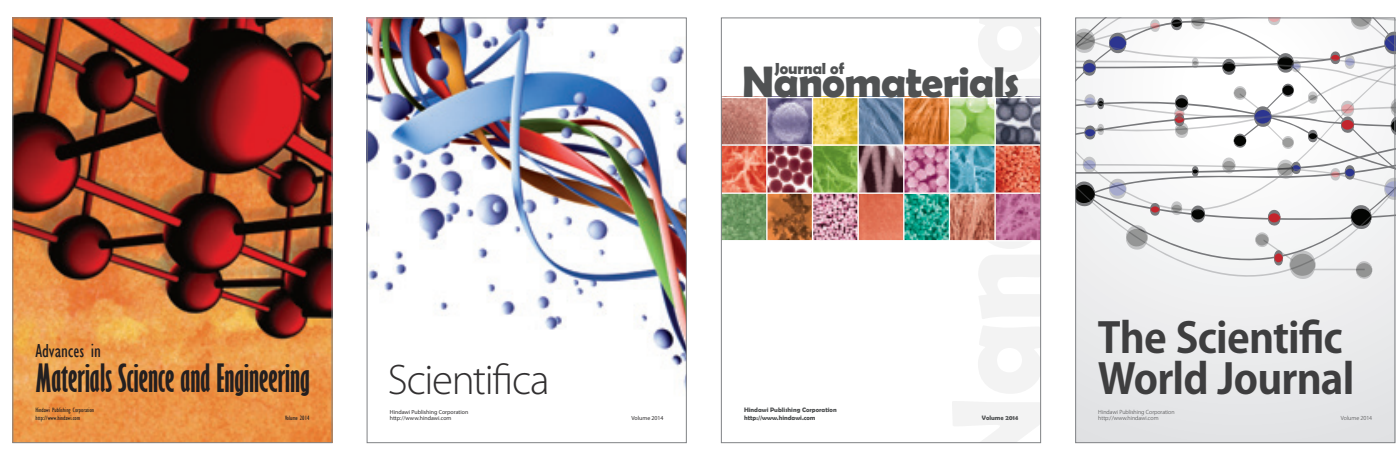

\section{The Scientific World Journal}
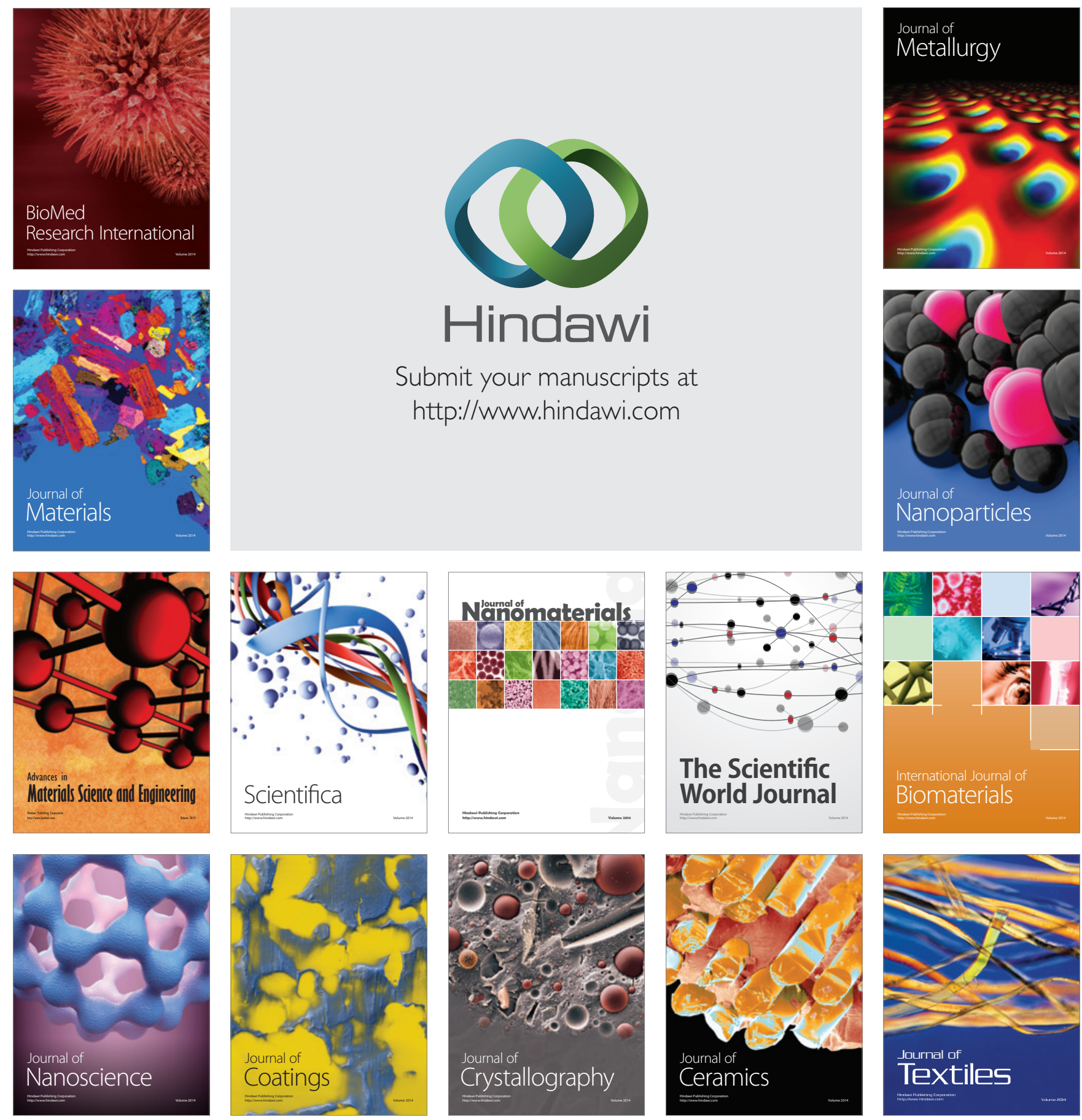